\title{
Flora of Singapore precursors, 24: Notes on Theaceae in Singapore
}

\author{
Y.K.L. Teo ${ }^{1}$, D.J. Middleton ${ }^{2}$ \& I.M. Turner ${ }^{2,3}$ \\ ${ }^{1}$ School of Biological Sciences, Nanyang Technological University, \\ 60 Nanyang Drive, 637551 Singapore \\ ${ }^{2}$ Singapore Botanic Gardens, National Parks Board, \\ 1 Cluny Road, 259569 Singapore \\ david_middleton@nparks.gov.sg \\ ${ }^{3}$ Singapore Botanical Liaison Officer, \\ Royal Botanic Gardens, Kew, Richmond, \\ Surrey, TW9 3AE, U.K.
}

\begin{abstract}
Clarification of the nomenclature of names used for species of Theaceae in Singapore is provided. Lectotypes are designated for Gordonia multinervis King, Gordonia concentricicatrix Burkill, Gordonia excelsa Blume var. sincapuriana Dyer, Gordonia grandis King and Pyrenaria acuminata Planch. ex Choisy.
\end{abstract}

Keywords. Gordonia, Polyspora, Pyrenaria, typification

\section{Introduction}

The limits of the family Theaceae have changed over time but the species in Singapore that are now included in this family as defined in APG IV (2016) belong to the genera Polyspora Sweet and Pyrenaria Blume. All species previously included in the genus Gordonia J.Ellis in Asia, including those in Singapore, have now been transferred to Polyspora (Orel et al., 2013; Choo et al., 2020). There are four species of Theaceae in Singapore, Polyspora multinervis (King) Orel et al., Polyspora penangensis (Ridl.) Niissalo \& L.M.Choo, Polyspora singaporeana (Wall. ex Ridl.) Niissalo \& L.M.Choo and Pyrenaria acuminata Planch. ex Choisy. Towards an account of the Theaceae for the Flora of Singapore, we here clarify some outstanding nomenclatural issues and typifications that affect the names of three of these four species.

\section{Typifications}

1. Polyspora multinervis (King) Orel, Peter G.Wilson, Curry \& Luu, Willdenowia 43(2): 308 (2013). - Gordonia multinervis King, J. Asiat. Soc. Bengal, Pt. 2, Nat. Hist. 59(2): 205 (1890); Ridley, Fl. Malay Penins. 1: 203 (1922); Keng, Gard. Bull Singapore 28: 247 (1976); Keng, Tree Fl. Malaya 3: 286 (1978); Keng, Gard. Bull. Singapore 37: 26 (1984); Keng, Concise Fl. Singapore, vol. 1, Gymn. Dicot. 50 (1990); Turner, Gard. Bull. Singapore 45: 219 (1993); Chong et al., Checkl. Fl. Singapore 46, 183, 
215 (2009). - TYPE: [Peninsular Malaysia], Perak, Scortechini 1968 (lectotype K [K000704260], designated here; isolectotypes G [G00354897], SING [SING0055530, SING0055531, SING0055532]).

Gordonia concentricicatrix Burkill, J. Straits Branch Roy. Asiat. Soc. 76: 153 (1917); Cubitt, J. Straits Branch Roy. Asiat. Soc. 78: 49 (1918); Keng, Tree Fl. Malaya 3: 285 (1978). - Polyspora concentricicatrix (Burkill) Orel, Peter G.Wilson, Curry \& Luu, Willdenowia 43(2): 306 (2013). - TYPE: [Peninsular Malaysia], Selangor, Rantau [Bantau] Panjang Reserve, 31 May 1916, Rawi [Rani] CF 878 (lectotype SING [SING0194807], designated here).

Distribution. Peninsular Malaysia, Singapore, Sumatra and Borneo.

Notes. King (1890) cited only one collection, Scortechini 1968, for Gordonia multinervis King but without mentioning where the material was deposited. We have located five specimens of the collection, in G, K and SING, and designate the most informative specimen at $\mathrm{K}$ as the lectotype.

In the protologue of Gordonia concentricicatrix Burkill, one of the collections cited was A. Rawi C.F. 898 but this was later changed to J.D. Watson \& Abdul Rani C.F. 878 by Cubitt (1918). Cubitt was likely mistaken as there are two separate collections on the same sheet, both numbered C.F. 878, but with different collectors, one of them Rani (incorrectly cited as Rawi by Burkill) and the other Watson. Keng (1984) noted that the 'type specimen' in SING consisted of two specimens mounted on the same sheet. We designate the left-hand plant on the sheet, the Rani collection which is separately barcoded, as lectotype.

2. Polyspora singaporeana (Wall. ex Ridl.) Niissalo \& L.M.Choo, Phytotaxa 458(2): 164 (2020). - Gordonia singaporeana Wall. [Numer. List n. 1457 (1829), nom. nud.] ex Ridl., J. Straits Branch Roy. Asiat. Soc. 73: 141 (1916); Burkill, J. Straits Branch Roy. Asiat. Soc. 76: 154 (1917); Ridley, Fl. Malay Penins. 1: 202 (1922); Keng, Tree F1. Malaya 3: 286 (1978); Keng, Gard. Bull. Singapore 37: 39 (1984); Keng, Concise Fl. Singapore, vol. 1, Gymn. Dicot. 50 (1990); Corner, Wayside Trees Mal., ed. 3, 723 (1988); Turner, Gard. Bull. Singapore 45: 219 (1993); Chong et al., Checkl. Fl. Singapore 46, 183, 215 (2009). - TYPE: Singapore, 1822, Wallich s.n. [EIC 1457] (lectotype K [K001113140], designated by Choo et al., Phytotaxa 458(2): 164 (2020)).

Gordonia excelsa Blume var. sincapuriana Dyer in Hooker, Fl. Brit. India 1: 291 (1875). - TYPE: Singapore, 1822, Wallich s.n. [EIC 1457] (lectotype K [K001113140], designated here and now homotypic with Gordonia singaporeana Wall. ex Ridl.).

Gordonia grandis King, J. Asiat. Soc. Bengal, Pt. 2, Nat. Hist. 59: 203 (1890), nom. illeg. non André (1880). - TYPE: [Peninsular Malaysia], Perak, Larut, 500$800 \mathrm{ft}$ [150-245 m], April 1885, King's collector 7468 (lectotype K [K001129805], designated here). 
Distribution. Peninsular Malaysia and Singapore.

Notes. Wallich s.n. [EIC 1457] is a mixed collection. The type of Gordonia singaporeana Wall. ex Ridl. designated above, Wallich s.n. [EIC 1457] [K001113140], is not from the same gathering as Wallich s.n. [EIC 1457] [G00355034]. Ridley, having worked at the Kew Herbarium prior to his publication of Gordonia singaporeana in 1916, was likely to have studied the Kew specimen, K001113140, rather than the Geneva specimen, making it more suitable for lectotypification as chosen by Choo et al. (2020).

Gordonia excelsa Blume var. sincapuriana Dyer is not the basionym of Gordonia singaporeana Wall. ex Ridl. at the rank of species despite the similarity in the names. Ridley (1916) makes no mention of the variety despite referring to Gordonia excelsa Blume from the same publication. If it were to be treated as the basionym, the different spelling of the variety would have to be adopted. Instead, Ridley is quite clearly taking up Wallich's original name for the species, albeit with a slightly different spelling (singaporiana vs singaporeana). Dyer (in Hooker, 1875) cited a number of syntypes for Gordonia excelsa var. sincapuriana from which we select the Kew specimen K001113140 as lectotype, rendering it homotypic with Gordonia singaporeana Wall. ex Ridl. The remaining syntypes cited by Dyer are Thomson s.n. from Singapore and Maingay s.n. from Malacca.

Gordonia grandis King is a later homonym. We have seen only one specimen that could be original material and select it here as lectotype.

3. Pyrenaria acuminata Planch. ex Choisy, Mém. Soc. Phys. Genève 14: 172 (1855); Miquel, Fl. Ned. Ind. 1, fasc. 2: 493 (1859); Hooker, Fl. Brit. India 1: 289 (1875); King \& Gamble, J. Asiat. Soc. Bengal, Pt. 2, Nat. Hist. 59: 200 (1890); Ridley, J. Straits Branch Roy. Asiat. Soc. 33: 49 (1900); Ridley, Fl. Malay Penins. 1: 200 (1922); Keng, Gard. Bull. Singapore 28: 247 (1976); Keng, Tree Fl. Malaya 3: 290 (1978); Keng, Gard. Bull. Singapore 33: 270 (1980); Corner, Wayside Trees Mal., ed. 3, 725 (1988); Keng, Concise Fl. Singapore, vol. 1, Gymn. Dicot. 50 (1990); Turner, Gard. Bull. Singapore 45: 219 (1993); Chong et al., Checkl. Fl. Singapore 74, 183, 217 (2009). - Gordonia (Camellia) acuminata Wall., Numer. List. (1831), nom. inval. - TYPE: [Peninsular Malaysia], Penang, 1822, Wallich s.n. [EIC 3664] (lectotype $\mathrm{K}$ [K000704225], designated here; isolectotype K-W (incorrectly labelled 3663) [K001110750]).

Distribution. Peninsular Malaysia, Singapore and Sumatra.

Notes. There has been some confusion over the labelling of duplicates of the type collection. Wallich s.n. [EIC 3664] [K001110751] in the East India Company Herbarium in Kew is not a duplicate of the lectotype Wallich s.n. [EIC 3664] [K000704225] in Kew's general collection and, therefore, not an isolectotype. The specimen labelled as 3663 in the East India Company Herbarium [K001110750], however, is almost certainly a duplicate of the specimen labelled 3664 in the general collection and is here treated as an isolectotype. 


\section{References}

APG IV (2016). An update of the Angiosperm Phylogeny Group classification for the orders and families of flowering plants: APG IV. Bot. J. Linn. Soc. 181: 1-20.

Choo, L.M., Niissalo, M.A., Leong, P.K.F. \& Khew, G.S. (2020). The complete plastome sequence of Gordonia penangensis Ridl. supports the transfer of Asian Gordonia into Polyspora (Theaceae). Phytotaxa 458(2): 159-166.

Cubitt, G.E.S. (1918). Gordonia concentricicatrix Burkill. J. Straits Branch Roy. Asiat. Soc. 78: 49-50.

Hooker, J.D. (1875). The Flora of British India, vol. 1. London: L. Reeve \& Co.

Keng, H. (1984). Florae Malesianae Precursores - LVIII, Part Two. The Genus Gordonia (Theaceae) in Malesia. Gard. Bull. Singapore 37: 1-47.

King, G. (1890). Materials for a flora of the Malayan Peninsula. Order XV. Ternstroemiaceae. J. Asiat. Soc. Bengal, Pt.2, Nat. Hist. 59(2): 185-206.

Orel, G., Wilson, P.G., Curry, A.S. \& Luu, H.T. (2013). Two new species of Polyspora (Theaceae) from Vietnam and new combinations for some Asian species. Willdenowia 43: 301-308.

Ridley, H.N. (1916). New and rare Malayan plants, series VIII. J. Straits Branch Roy. Asiat. Soc. 73: 139-146. 